The Labore Journal of Economics

11 : 2 (Winter 2006) pp. 107-121

\title{
Role of the Futures Market on Volatility and Price Discovery of the Spot Market: Evidence from Pakistan's Stock Market
}

\author{
Safi Ullah Khan*
}

\begin{abstract}
This paper focuses on the role of the financial futures market in the volatility of Pakistan's stock market and determines whether the stock futures price is capable of providing some relevant information for predicting the spot price. The Generalized Autoregressive Conditional Heteroscedasticity (GARCH) approach is used to measure volatility in the spot and the futures market and to analyze the relationships between spot and futures market volatility. Causality and feedback relationships between the two markets are analyzed and determined through the Vector Error Correction Model (VECM). Empirical results support the evidence that spot prices generally lead the futures prices in incorporating new information, and that volatility in the futures market does not increase volatility in the spot market. Rather the study finds more consistent support for the alternative hypothesis that volatility in the futures market may be an outgrowth of the volatile spot market.
\end{abstract}

\section{Introduction}

Following the March 2005 stock market crash in Pakistan, considerable blame for the market crash was laid at the doors of the financial futures market and many people in Pakistan even demanded the abolition of trading in financial futures contracts as it was mainly blamed for excess volatility in stock prices. This paper investigates the role of the financial futures market in the volatility of Pakistan's stock market and determines whether the stock futures price is capable of providing some relevant information for predicting the spot price. The Karachi Stock Exchange (KSE) is the largest of the three exchanges of Pakistan. It began operations with a 50 share index in 1950. As the market grew, a representative index was needed. The KSE-100 was introduced on

\footnotetext{
* The author is a PhD Fellow at Mohammad Ali Jinnah University, Islamabad and a faculty member at the Kohat University of Science and Technology, Kohat, NWFP, Pakistan.
} 
November 1, 1991 and remains the most generally accepted measure of the Exchange. The KSE-100 Index is a capital weighted index and consists of 100 companies representing about 90 percent of the market capitalization of the Exchange. As of March 31, 2006, 663 companies were listed with a market capitalization of Rs. 3,257.062 billion (US \$ 54.28) and having listed capital of Rs. 486.489 billion (US $\$ 8.11$ billion). The KSE-100 Index closed at 11485.90 on March 31, 2006.

Exchange traded index futures were first introduced on the KSE-100 index on July 1, 2001. In Pakistan, futures contracts mature in thirty days, and the last day for trading in a contract is the last Friday of each month for those contracts that have reached maturity.

This paper strengthens the evidence that futures market volatility does not induce cash market volatility. Rather, this study finds more consistent support for the alternative hypothesis that volatility in the futures market may be an outgrowth of the volatile spot market.

The rest of the paper is organized as follows: The second section presents a brief literature overview, while the third section presents the data and methodology. The final section provides the conclusions and findings of the study.

\section{Literature Review}

There is little agreement among researchers as to the effect of futures contracts on the underlying ready market. Although there is a general perception that stock price volatility has increased due to the introduction of derivatives, the empirical evidence regarding this issue has not led researchers to a unanimous conclusion and the evidence is far from conclusive. In other words, conflicting arguments and empirical results exist as to why futures trading may increase or decrease volatility in the cash market.

Many researchers report results that support the general perception that futures trading has provoked volatility in the spot market. There are four contrasting opinions regarding the role of futures on stock prices and the vice versa. First, futures' trading has provoked volatility in the spot market, perhaps through excessive, and largely irrational, speculative activities. Moreover, uninformed speculation is thought to be greater in the futures markets due to the lower transaction costs associated with it (Sharown and Gregary, 1995). Figlewski (1981) also contends that if increased hedging demand is not offset by enough speculation, or if futures 
traders are less informed than cash market participants, volatility in the cash market is increased. Prior empirical studies have attempted to establish the impact of futures trading on cash markets by comparing cash market volatility over the pre- and post-futures trading eras. For instance, Mabery, Allen and Gillbret (1989) conclude that volatility in spot markets rose subsequent to the introduction of the index futures. Harris (1989) reports a statistically significant increase in volatility due to futures trading. Lee and Ohak (1992) find that, following the introduction of index futures, the volatility of stock indices in Australia, Hong Kong, Japan, the U. K. and the U.S rose significantly. Antoious and Holmes (1995) reported that volatility in the spot market increased after the introduction of futures trading. They argue that the apparent volatility increase is the result of futures trading expanding the channels through which information flows into the market. Herbest and Marberly (1992) suggest that one of the main functions of the futures market is to act as a conduit for transmitting economic news to uniformed investors.

In the second view on the role of futures in determining stock prices, several studies deny any increase in spot market volatility resulting from the introduction of index futures trading. They conclude that futures attract more informed traders to the cash market, making it more liquid and, if anything, less volatile (Peridi and Koutmos, 1997). Figlewski (1981) notes that the ability of cash market participants to hedge with futures lowers volatility and improves the functioning of the cash market by reducing the risk premium embedded in cash price.

Illustrating the third view of futures and stock prices, some studies on the relationship between futures trading and stock market volatility find no such impact of futures trading on the stock market volatility after the introduction of the futures trading. Galloway and Miller (1997), for instance, investigating the relationship between stock index futures trading and stock return volatility in the Mid Cap 400 stock index after the introduction of the stock index futures, document a significant decrease in return volatility and systematic risk, and a significant increase in trading volume for the Midcap 400 stocks after the introduction of the Midcap 400 index futures. They find no difference in the behavior of the Midcap 400 stocks and no evidence of a relation between index futures trading and volatility in the stock market. Periclly and Koutmos (1997), using daily closing prices for S \& P 500 index for a period from January 1953 to December 1994 report that no structural change has occurred in the conditional variance in the period following the introduction of the stock index futures and options. Darat and Rehman (1995) examined the role of index futures trading in spot market volatility for S\&P 500 index 
prices and S\&P 500 futures prices for a period from November 1987 to 1997, and their empirical results suggest that index futures may not be blamed for the observed volatility in the spot market. Rather, they find strong and more consistent support for the alternative posture that volatility in the futures markets is an outgrowth of a turbulent cash market. Others who find similar results include Sharown and Gregary (1995), Board and Scuttliffe (2001), Franklin (1988), Edwards and Franklin (1988), Bessembinder and Senguin (1992), Faff and Mckenzie (2002), Ellueca and Lafuente (2003), Andreas and Koutmos (1997), Chan, Chan, and Karolyi (1991).

Illustrating an alternative way of looking at futures and stock prices, some researchers focus on the Granger Causal relation between the spot and the futures markets. This includes Schwert (1990), Stoll and Walley (1990), Abhayankar et al (1995), and Annand et al (1986) to mention a few. Some authors have found that futures volume has no effect on changes in the volatility of the spot market. Significant among them include Smith (1989), Santoni (1989).

Summarizing the results of the above mentioned articles and studies, existing empirical studies do not imply that an optimal level of futures trading volume to cash market volume exists. An empirical investigation in an emerging market such as that of Pakistan is required to establish the extent that level of futures trading affects cash price volatility and whether trading in the financial futures contracts play any role in the price discovery and the volatility of stock prices.

\section{Data and Methodology}

This paper uses the time series of daily closing value of the Karachi Stock Exchange (KSE-100) Index and the daily total nominal value of the futures contracts traded on the KSE-100 Index. Data on futures contracts were obtained from the KSE-100 Index online database while closing values for the stock index were obtained from yaboofinance.com. Trading in futures on the KSE-100 index started on July 1, 2001. The choice of the time period under study for stock futures contracts was dictated by the fact that data on the futures contracts is available from Jan 1, 2003. This study, therefore, covers the period from January 1, 2003 to December 9, 2005 for futures contracts. For the stock index, data covered the January 1, 1997 to December 9, 2005 period. Returns for both index and futures contracts are calculated by taking the first difference of $\log$ of two consecutive days.

$$
R_{t}=\operatorname{Ln}\left(P_{t} / P_{t-1}\right)
$$


To assess the distributional properties of the daily stock prices and the daily stock index futures changes, various descriptive statistics are reported in Table-1. The descriptive statistics for the two returns series are the mean, standard deviation, first to twelfth order autocorrelation, skewness, excess kurtosis, the Ljung-Box statistic (for testing the hypothesis that all autocorrelations up to lag 12 are equal to zero), and the Jarque-Bera normality statistic.

Table-1: Summary Statistics for Daily Spot and Futures Returns

\begin{tabular}{lcccc}
\hline & \multicolumn{3}{c}{ Spot Returns } & Futures Returns \\
\hline & Full Period & Post Futures & Pre Futures & Futures \\
\hline Mean & 0.102 & 0.187 & 0.005 & 0.031 \\
Standard & 1.866 & 1.574 & 2.156 & 2.035 \\
Deviation & & & & \\
Maximum & 13.612 & 8.879 & 13.612 & 19.401 \\
Minimum & -12.378 & -7.449 & -12.378 & -16.738 \\
Kurtosis & 5.388 & 2.891 & 5.234 & 48.412 \\
Skewness & -0.166 & -0.108 & -0.122 & 1.290 \\
ADF Test Z(t) & $-13.013^{* *}$ & $-9.261^{* *}$ & $-8.940^{* * *}$ & $-11.077^{* *}$ \\
(Q)12 & 27.62 & & & 201.94 \\
J-B Test & 211.59 & & & 5232.15 \\
\hline
\end{tabular}

Note: The figures for the mean, standard deviation, maximum, and minimum are all in percentages. The full period for stock returns are divide into two groups namely the pre and the post futures period.

** shows significance at $1 \%$ level.

The full period for the stock returns is divided into two groups namely the pre-and the post-futures periods. The second column of Table-1 provides computed values for the full period of the stock returns. This period is from July 1, 1997 to December 9, 2005. The third column of Table-1 presents values for the post-futures period (i.e, Jan 1, 2003 to December 9, 2005 for stock returns). The fourth column of the table contains computed values of pre-futures time period for spot returns (i.e, July 1, 1997-December 31, 2002). The kurtosis, skewness and Jarque-Bera statistics in Table-1 indicate that the null hypothesis of a normal 
distribution is rejected for both the series. Table-1 also reports Augmented Dickey Fuller test statistics for unit root in the returns series. Returns series are stationary.

The independence assumption of the $\mathrm{T}$ observation in both the series is tested by calculating the first to twelfth order autocorrelation coefficients. The statistical significance of any autocorrelation coefficient can be judged by its standard error. Barlett (1946) has shown that if a time series is purely random, the sample autocorrelation coefficients are approximately, $\rho_{\mathrm{k}} \sim \mathrm{N}(0,1 / \mathrm{n})$. Using the usual approximation of standard error of the estimated autocorrelation coefficients, first-order autocorrelation is not found for the stock returns series; it was found for the futures returns series but higher order autocorrelation appears to exist. The Ljung-Box Q (12) statistics for the cumulative autocorrelation up to twelfth-order autocorrelation in the two returns series are both greater than 21.02 (the $5 \%$ critical value from a $\chi^{2}$ distribution with 12 degrees of freedom) implying that the hypothesis of independence in daily returns should be rejected. Overall, these results reject the independence assumption for the two returns series of Pakistan's stock market and warrant the use of GARCH specifications in modeling volatility for Pakistan's stock and financial futures markets.

\subsection{Modeling the Volatility}

To determine whether stock index futures increase stock price volatility, volatility in the ready and futures markets is examined using Generalized Autoregressive Conditional Heteroskedasticity (GARCH). This approach is a widely used and most effective measure in estimating and measuring volatility clustering in asset returns. Bolerslev (1986) extended the ARCH model, introduced by Engle (1982), to the GARCH model which allows for more flexible lag structures. By letting $\varepsilon_{\mathrm{t}}$ serve as a random error process, $h_{t}$ as the variance of $\varepsilon_{t}$, and $\psi_{t}$ as the information set of all information through time $t$, for a return series, $R_{t}$, the GARCH $(p, q)$ model is given by:

$$
\begin{aligned}
& R_{t}=\omega+\sum_{i=1}^{m} \phi R_{t-i}+\varepsilon_{t} \\
& \varepsilon_{t} \mid \psi_{t-1} \sim N\left(0, h_{t}\right),
\end{aligned}
$$


Where $R_{t}$ is an index of daily stock returns in logarithms forms as defined by equation (1) or futures returns for futures contracts, and conditional variance of returns $h_{t}$, is specified as:

$$
h_{t}=\alpha_{o}+\sum_{i=1}^{p} \alpha_{i} \varepsilon_{t-i}^{2}+\sum_{i=1}^{q} \beta_{i} h_{t-i}
$$

The parameters in equation (3) should satisfy: $p \geq 0, q \geq 0, \alpha_{o} \geq$ $0, \alpha_{1} \geq 0, i=1, \ldots \ldots, p, \beta_{i} \geq 0, i=1, \ldots \ldots, q$. According to Akgiray (1989), allowing the conditional variances to depend on the past realized variances is particularly consistent with the actual volatility pattern of the US stock markets where there are both stable and unstable periods.

The orders of $p$ and $q$ in this paper are $(1,1)$ on the basis of the values of the Akaike Information Criteria. Therefore, the $\operatorname{GARCH}(1,1)$ model is used in this study. According to the GARCH (p, q), the conditional variance of $\varepsilon$ at time $t$ depends not only on the squared error term in the previous time period [as is in $\mathrm{ARCH}(1)]$ but also on its conditional variance in the previous period. In this case, both $\alpha_{1}$ and $\beta_{1}$ will be significant.

To model the spill-over effect of volatility in market A on market B, a lagged squared error term from the mean equation of the GARCH model for market A may be introduced into the GARCH model for market B as an explanatory variable in the conditional variance equation. The estimate of the coefficient of the lagged squared error term is then examined, and a significant estimate would suggest a spill-over effect. This spill-over effect from stock market to futures market or vice versa can be captured by the following specification:

$$
h_{t}=\alpha+\sum_{j=1}^{k} \beta_{i} \varepsilon_{t-i}^{2}+\sum_{i=1}^{p} \phi h_{t-i}+\sum_{\vartheta}^{\nu} \omega \varepsilon_{A t-k}^{2}
$$

where the $\varepsilon_{\text {At-k }}^{2}$ 's are previous periods' shocks to either stock or futures market.

In the estimation of the GARCH model, one can begin with a general specification of the mean equation (2) and the variance equation (3). The orders of the AR and MA processes in the mean equation (2) are determined by the partial autocorrelation (PACF) and the autocorrelation function (ACF) of the returns series for both stock index and the futures contracts. The final GARCH specification is decided by looking at the 
properties of the standardized residuals, which are conventional residuals divided by their one step ahead conditional standard deviation. If the model is correctly specified these should be independently identically distributed with mean zero and variance one. The best specification for KSE-100 Index and futures contracts is GARCH $(1,1)$ with the mean equations of ARMA $(3$, $3)$ for stock index and ARMA $(2,2)$ for futures contracts. Table- 2 presents the estimation results of the GARCH model. The estimates of the GARCH $(1,1)$ model for both stock index and futures contracts show that all the parameters in the mean and the variance equations are statistically significant and the values of the estimated parameters $\alpha, \alpha_{1}$ and $\beta_{1}$ satisfy $\alpha$ $>0, \alpha_{1}, \beta_{1}>0$. The Ljung-Box Q (36) statistics for the standardized residuals indicate that most of the linear dependence (autocorrelation) in the mean and variance has been captured by the GARCH $(1,1)$ specification.

Panel A and B of Table-2 present GARCH estimations for mean and variance equations for stock index and futures returns. These results reported in panel A show that under the variance equation for stock returns, the coefficient for the futures return is not statistically significant, implying that volatility in the futures market does not contribute to the volatility of stock returns. For futures returns as a dependent variable as reported in panel $\mathrm{B}$, under the variance equation the coefficient of the stock returns is highly significant. This implies that an increase in the spot market volatility increases the volatility in the futures market. In other words, there is volatility spill-over from the stock index to the futures contracts series. This suggests that the futures market is not responsible for the increased volatility in the spot market. Rather volatility in the futures market may be an outgrowth of the turbulent stock market.

The coefficients describing the conditional variance process, $\alpha_{1}$ and $\beta_{1}$, are highly significant for both futures and spot returns. This in turn implies that current volatility is a function of last period's squared innovation and last period's volatility. This phenomenon of volatility clustering has a long history as an empirical regularity of emerging markets that characterize high speculative prices.

The persistence of shocks to volatility is measured by $\alpha+\beta$ in the GARCH $(1,1)$ model. According to Engel and Bollerslev (1986), if $\alpha+\beta=1$ in the GARCH $(1,1)$ model, a current shock persists indefinitely in conditioning the future variance. Chou (1988) states that because the sum $\alpha_{1}+\beta_{1}$ represents the change in the response function of shocks to volatility persistence, a value greater than unity implies that the response function of volatility increases with time and a value less than unity implies that shocks 
decay with time. The closer to unity the value of persistence measure, the slower is the decay rate (Hassan et a1., 2006). For both spot and futures return series, $\alpha_{1}+\beta_{1}$ is very close to unity, i.e., suggesting that shocks are explosive and that current innovations remain important for multi-step ahead forecasts. According to Poterba and Summers (1986) a significant impact of volatility on stock prices can only occur if a shock to volatility persists over a long time. A useful measure for such an assessment is the half-life (HL) which measures the time it takes for an innovation to die out. The half-life of volatility persistence can be calculated as follows: $\ln (0.5) / \ln$ (3). For KSE it takes approximately two business days for the impact of daily volatility shock to diminish by one-half $[(2=\ln (0.5) / \ln (0.71)]$ and for futures returns it is almost nine days for shocks to diminish by one-half.

Table-2: GARCH Model: Relationship between spot and the futures returns volatility

$$
R_{t}=\phi R_{t-1}+\varepsilon_{t} \text {, and } h_{t}=\alpha_{o}+\alpha_{1} \varepsilon_{t-1}^{2}+\beta_{1} h_{t-1}+\delta r e t^{*}
$$

\begin{tabular}{|c|c|c|c|}
\hline Panel A: & Stock Returns & Log likelihood & 2028.36 \\
\hline $\begin{array}{l}\text { Parameters } \\
\text { ARMA }\end{array}$ & Coef. & Std. Err. & $\mathrm{Z}$ \\
\hline$\Omega$ & 0.002485 & 0.000399 & 6.22 \\
\hline$\Phi$ & 0.089682 & 0.038973 & 2.30 \\
\hline \multicolumn{4}{|l|}{ Variance Equation } \\
\hline$\alpha_{o}$ & $1.15 \mathrm{E}-05$ & $2.30 \mathrm{E}-06$ & 4.98 \\
\hline $\mathrm{ARCH}(1)$ & 0.264675 & 0.047633 & 5.556499 \\
\hline GARCH(1) & 0.705991 & 0.041974 & 16.81952 \\
\hline$\omega \quad$ (Futures) & $-4.25 \mathrm{E}-06$ & $1.52 \mathrm{E}-05$ & -0.27878 \\
\hline$Q(36)^{S D R}$ & 30.53 & Prob (Q) & 0.726 \\
\hline Panel B: & utures returns & Log likelihood & -124.5354 \\
\hline$\Omega$ & 0.013949 & 0.005699 & 2.44 \\
\hline$\Phi$ & -0.10245 & 0.054783 & -1.87 \\
\hline \multicolumn{4}{|l|}{ Variance Equation } \\
\hline$\alpha_{o}$ & 0.000496 & $6.30 \mathrm{E}-05$ & 7.87 \\
\hline $\mathrm{ARCH}(1)$ & 0.077951 & 0.004375 & 17.81 \\
\hline GARCH(1) & 0.939518 & 0.002537 & 370.37 \\
\hline$\omega$ (Stock Returns) & 0.189586 & 0.015558 & 12.18 \\
\hline$Q(36)^{S D R}$ & 42.04 & Prob (Q) & 0.226 \\
\hline
\end{tabular}

Note: ret* stands for future o $r$ stock returns in the variance equation. $Q(36)^{S D R}$ are Ljung-Box $Q(36)$ statistics for standardized residuals 


\subsection{Co-Integration Test}

The purpose of the co-integration test is to determine whether a stable relationship exists between the levels of two economic variables. Table-3 presents results of the co-integration test. It is evident that the futures price variable with the $\mathrm{ADF}$ statistics is significant at the $99 \%$ level. This implies that the hypothesis that some linear combinations of the spot price and the futures prices are $I(1)$ can be rejected at the $1 \%$ level of significance and a long run stable relationship between the spot and the futures prices can be expected.

Table-3: Results of co-integration test

\begin{tabular}{|c|c|c|c|c|}
\hline Test & & 1\% Critical Value & 5\% Critical & $10 \%$ Critica \\
\hline $\mathrm{Z}(\mathrm{t})$ & -46.539 & -3.43 & -2.86 & -2.57 \\
\hline
\end{tabular}

One now needs to determine which price leads and which price follows. This is addressed in the following section.

\subsection{Vector Error Correction Model (VECM)}

Lein (1996), argue that if the two price series are found to be cointegrated, a VAR model should be estimated along with the errorcorrection term which accounts for the log-run equilibrium between spot and futures price movements. The error correction model (ECM) for cointegrated variables is commonly interpreted as reflecting partial adjustment of one variable to the other. It has been proven that two variables, which are co-integrated, have an error correction model representation. ECM is given in the following equations.

$$
\begin{aligned}
& R_{t}^{S}=\alpha_{1}+\sum_{i=1}^{m} \beta_{i 1} R_{t-i}^{f}+\sum_{i=1}^{n} \gamma_{i 1} R_{t-i}^{S}+\theta_{S} Z_{t-1}+\varepsilon_{i 1} \\
& {\left[R_{t}^{f}=\alpha_{2}+\sum_{i=1}^{m} \beta_{i 2} R_{t-i}^{S}+\sum_{i=1}^{n} \gamma_{i 2} R_{t-i}^{f}+\theta_{f} Z_{t-1}+\varepsilon_{i 2}\right]}
\end{aligned}
$$

Where, $R_{\mathrm{t}}^{\mathrm{s}}$ and $\mathrm{R}_{\mathrm{t} \text {, }}^{\mathrm{f}}$ are the returns at time $t$ for the index and the futures contracts respectively. If some of the $\beta_{\mathrm{i} 1}$ values are statistically not zero, then $\mathrm{R}_{\mathrm{t}-1}^{\mathrm{f}}$ is said to Granger cause $R^{\mathrm{s}}{ }_{\mathrm{t}}$. Similarly, if some $\beta_{\mathrm{i} 2}$ 's are not zero, then $R_{t}^{s}$ are said to Granger cause $R_{t}^{f}$. If both $\beta^{i}$ 's are significant then a feedback relationship is said to exist. If both the parameters are statistically equal to 
zero, then both price series move contemporaneously. A standard F-test can be applied to test the null hypothesis that spot prices fail to Granger cause the futures prices or vice versa. Using the Akaike's (1969) Final Prediction Error criterion for determining the auto-regressive lag length, equation (3) and (4) are estimated for $m=3$ and $n=4$ by the least squares for futures and spot prices.

$Z_{t-1}$ is the error correction term, which measures how the dependent variable adjusts to the previous period's deviation from longrun equilibrium. The no-arbitrage principle concludes that there is a cost-of-carry relationship between the spot and the futures prices depending on the time to maturity. Thus the $Z_{t}$ should assume the following form: $Z_{t-1}=R_{t-1}^{s}-C-\alpha R_{t-1}^{f}$, where $\alpha$ is the co-integrating vector and $C$, the constant, is per period cost of carry. $\theta_{s}$ and $\theta_{f}$ are interpreted as the speed of adjustment parameters. A set of equations is estimated in a descending order of generality. The results of the VECM are given in Table-4. According to the Swartz Bayesian and the Loglikelihood ratio statistics, the appropriate lag length of the VECM model is four. Table-4 shows that for both equations of changes in lagged spot and futures prices, the error correction term coefficients are statistically significant. It is noted that $\theta_{s}=-.0328191$, while $\theta_{\mathrm{f}}=6.39$ indicating that the future price series, $R^{f}$, adjusts far more rapidly to the previous period's deviation from long-run than the spot price series. On the whole, two main conclusions follow from the error correction mode1: First, for eq. (3), all the lagged differences of the futures prices are insignificant. On the other hand, for equation (4), the lagged differences of the spot price are very significant. This suggests that the spot price has much more explanatory power for futures prices than the futures prices do for the spot. Moreover, overall, the estimated equation (3) is much better than the eq. (4) in terms of the $R^{2}$. One can conclude that the changes in the futures prices are well explained by the changes in the lagged spot prices and futures prices. Additionally, while the lagged spot prices play a role in eq. (4), the changes in the lagged futures prices are not significant in eq. (3). It indicates again that the spot market dominates the futures market but not the other way around. 
Table-4: Results of Vector Error Correction Model

\begin{tabular}{|c|c|c|c|}
\hline \multicolumn{4}{|c|}{ log likelihood 1640.783} \\
\hline \multirow{2}{*}{$\begin{array}{c}\text { Stock Returns } \\
\text { Parameters } \\
\end{array}$} & \multicolumn{3}{|c|}{ Futures Returns } \\
\hline & Coeff. & Parameters & Coeff. \\
\hline$\alpha_{1}$ & 0.0002 & $\alpha_{2}$ & -0.00003 \\
\hline$\theta_{\mathrm{s}}$ & $-0.0328^{* * * *}$ & $\theta_{\mathrm{f}}$ & $6.3971^{*}$ \\
\hline $\mathrm{R}_{\mathrm{t}-1}^{\mathrm{s}}$ & $-0.6872^{*}$ & $R_{t-1}^{s}$ & $-4.4614^{*}$ \\
\hline $\mathbf{R}_{\mathrm{t}-2}^{\mathrm{s}}$ & $-0.5692^{*}$ & $R_{t-2}^{s}$ & $-2.7086^{*}$ \\
\hline $\mathrm{R}_{\mathrm{t}-3}^{\mathrm{s}}$ & $-0.2286^{*}$ & $\mathrm{R}_{\mathrm{t}-3}^{\mathrm{s}}$ & -0.2226 \\
\hline $\mathrm{R}_{\mathrm{t}-1}^{\mathrm{f}}$ & $-0.0095^{*}$ & $R_{t-1}^{f}$ & $0.6316^{*}$ \\
\hline $\mathrm{R}_{\mathrm{t}-2}^{\mathrm{f}}$ & -0.0054 & $R_{t-2}^{f}$ & $0.3309^{*}$ \\
\hline$R_{t-3}^{f}$ & -0.0029 & $R_{t-3}^{f}$ & $0.1211^{*}$ \\
\hline $\mathrm{R}^{2}$ & 0.38 & $\mathrm{R}^{2}$ & 0.77 \\
\hline \multicolumn{4}{|c|}{ Co-integrating } \\
\hline $\mathbf{R}_{\mathrm{t}-1}^{\mathrm{s}}$ & 1 & - & - \\
\hline $\mathrm{R}_{\mathrm{t}-1}^{\mathrm{f}}$ & -0.356 & 0.018 & $-19.4^{*}$ \\
\hline $\mathrm{C}$ & 0.0006 & - & - \\
\hline
\end{tabular}

Note: ** shows significance at $5 \%$ and * shows significance at $1 \%$ level.

\section{Conclusion}

This paper focuses on the role of the futures market by taking Pakistan's turbulent stock market as an example and determines whether the stock futures price is capable of providing some relevant information for predicting the spot price. Results suggest that the spot price has much more explanatory power for futures prices than the futures prices do for the spot price. Under the GARCH model, results show that volatility in the futures markets may not contribute to the volatility of stock returns suggesting that the futures market is not responsible for the increased volatility in the spot market. Empirical findings support the evidence that futures trading may not be blamed for increased volatility in the spot market. On the contrary, these results support the alternative hypothesis that volatility in the futures market may in itself be an outgrowth of the volatile spot market. Consequently, more focus on other and more plausible sources of instability in the stock market, including investor psychology, capital market reforms, trading technology and market microstructures, are needed. 


\section{References}

Abhay N Abhayankar, 1995, "Return and Volatility dynamics in the FT-SE 100 stock index and stock index futures market", Journal of Futures markets, 15(14): 457-476.

Akaike, H.L, 1969, "Fitting Autoregressions for prediction", Annals of Finance, 5: 1155-75.

Akairay, V., 1989, "Conditional heteroscedasticity in time series of stock returns: evidence and forecasts”, Journal of Business, 62(1), 55-80.

Anand K. Bhattacharya, Anju Rameei, and Balasubramani Ramjee, 1986, "The causal relationship between futures price volatility and the cash price volatility of GNMA securities", The Journal of Futures Markets, 16 (1): 29-54.

Andreas Pericli, Gregory Koutmos, 1997, "Index futures and options and stock market volatility”, Journal of Futures Markets, (18): 957-984.

Antoniou, A. and P. Homes, 1995, "Futures Trading and Stock Price Volatility: Evidence for the FTSE-100 Stock Index Futures”, Journal of Banking and Finance 19: 117-29.

Bartlet, M. S., 1946, “On the theoretical specification of sampling properties of auto correlated time series”, Journal of Royal Statistical Society, series B, 27: 27-41.

Bartlett, M.S., 1946, "On the Theoretical Specification of Sampling Properties of Autocorrelated Time Series”, Journal of Royal Statistical Society, Series B, vo1. 27, pp. 27-41.

Bessimender, H. and P. J. Segian, 1992, "Futures trading activity and price volatility”, Journal of Finance 47: 2015-34.

Board, J. and C.M.S. Sutcliffe, 1995, "The relative volatility of the markets in equities and Stock Index futures”, Journal of Business Finance and Accounting 22: 201-23.

Bollerslev, T., 1986, "Generalized Autoregressive Conditional Heteroscedasticity”, Journal of Econometrics 31: 307-27. 
Chan, K., Chan K., and Karolyi G., 1991, "Intraday volatility in the stock index and stock index futures markets", The Review of Financial Studies 4: 652-84.

Chou, R.Y., 1988, "Volatility persistence and Stock valuations: Some empirical evidences using GARCH", Journal of Applied Econometrics 3, 279-294.

Darat, A.F. and S. Rehman, 1995, "Has Futures trading activity caused stock price volatility”, Journal of Futures markets 15: 537-56.

Edwards, Franklin R., 1988, "Futures trading and cash market volatility: Stock index and interest rate future", The Journal of Futures Markets 8 (4): 421-53.

Ellueca, E.J. and Lafuente, A., 2003, "The effect of spot and futures trading on stock index market volatility: A nonparametric approach”, The Journal of Futures Markets, Vol. 23, 9: 841-862.

Enge1, F. R., and T. Bollerslev, 1986, "Modeling the persistence of conditional variances", Economic Reviews 5, 1-50.

Engle, R., 1982, "Autoregressive conditional heteroscedasticity with estimates of variance of United Kingdom”, Econometrica, 50, 597622.

Faff, W.R. and Mckenzie D. M., 2002, “The impact of Stock Index Futures Trading on daily returns seasonality”, Journal of Business, 75(1): 95117.

Figelwiske, K., 1981, "Futures Trading and volatility in GNMA futures", Journal of Finance 36: 445-56.

Franklin R., 1988, "Does futures trading increases stock market volatility"? Financial Analysts Journal 44,1, p.63-88.

Galloway, T.M. and James M., 1987, "Index Futures trading and stock return volatility: Evidence form the introduction of Mid-Cap 400 Index Futures”, The Financial Review 32, 4: 845-876.

Harris, L., 1989, "Cross-security tests of the mixture of disturbances hypothesis”, Journal of Quantitative Analysis 21, 39-46. 
Hassan, K.B., Haque, M. and Lawrence S. B., 2006, "An empirical analysis of emerging stock markets of Europe”, Quarterly Journal of Business and Economics 45, 1/231-52.

Herbest, A. and E. Maberley, 1992, "The Informational role of the end-ofthe-day returns in Stock Index Futures", Journal of Futures Markets $12,595-601$.

Lee, S. K., and Ohak, Y., 1992, "Stock Index futures listing and structural changes in time varying volatility”, Journal of Futures Markets 12: 493-509.

Lein, D.D., 1996, "The effect of the Co-integration Relationship on Futures hedging: a note", Journal of Futures Markets 16: 733-89.

Maberly, E., D., Ellen and R. Gilberth, 1989, "Stock Index futures and cash market volatility”, Financial Analyst Journal 4:, 75-77.

Percili, A. and Koutmous, G., 1997, "Index Futures and Options and Stock Market Volatility”, Journal of Futures Markets 17, 957-74.

Poterba, J.M., and L.H. Summers, 1986, "The persistence of volatility and stock market functions”, American Economic Review 76, 11411151 .

Santoni, G.J., 1987, "Has programmed trading made stock prices more volatile?” Federal Reserve Bank Review 4, 18-29.

Schwert, G.W., 1990, "Stock market volatility”, Financial Analyst Journal $46,23-34$.

Sharon Brown-hruska, Gregory Kuserk, 1995, "Volatility, Volume and the notion of balance in the S\&P 500 cash and futures market", Journal of futures markets 15 (6): -677-89.

Smith, C.W., 1989, "Market Volatility: Causes and consequences”, Cornell Law Review 74, 953-62.

Stoll, R.H., and Whalley, R.E., 1990, "The dynamics of Stock Index and Stock Index Futures Returns”, Journal of Financial and Quantitative Analysis 25, 441-68. 